\title{
Targeted silencing of CXCL1 by siRNA inhibits tumor growth and apoptosis in hepatocellular carcinoma
}

\author{
KE-QI HAN $^{1 *}$, XUE-QUN HE ${ }^{1}$, MENG-YU MA ${ }^{1}$, XIAO-DONG GUO ${ }^{1}$, XUE-MIN ZHANG $^{1}$, \\ JIE CHEN $^{1}$, HUI HAN ${ }^{1}$, WEI-WEI ZHANG ${ }^{1}$, QUAN-GANG ZHU ${ }^{2}$ and WEN-ZHAO ZHAO ${ }^{3 *}$ \\ Departments of ${ }^{1}$ Oncology and ${ }^{2}$ Pharmacy, Shanghai Yueyang Hospital of Integrated Traditional Chinese \\ and Western Medicine, Shanghai University of Traditional Chinese Medicine, Shanghai 200437; \\ ${ }^{3}$ Department of Surgery, Affiliated Hospital of Henan Science and Technology University, \\ School of Medicine, Luoyang, Henan 471003, P.R. China
}

Received July 22, 2015; Accepted September 4, 2015

DOI: 10.3892/ijo.2015.3203

\begin{abstract}
Hepatocellular carcinoma (HCC) is an aggressive malignancy and a major cause of cancer-related mortality worldwide. Our previous study shows that chemokine (C-X-C motif) ligand 1 (CXCL1) was upregulated and CXCR1 was downregulated in tumor tissues as compared to peritumor tissues by chemotaxis assay. As the status of CXCL subgroups and their receptors affect progression of $\mathrm{HCC}$, we evaluated potential mechanisms of CXCL1 associated with anticancer effects in HCC based on our previous study. The effects of targeting CXCL1 by RNA interference (RNAi) on the proliferation and apoptosis of CBRH-7919 cells were observed in vitro and in vivo. Additionally, whether CXCL1 knockdown significantly reduce the activity of STAT3, NF- $\mathrm{BB}$ and HIF-1 or not were also estimated. RNAi of CXCL1 in the CBRH-7919 cells decreased the growth of tumors in nude mice by inhibited cells proliferation and induced apoptosis. In conclusion, these findings suggest that CXCL1 plays critical roles in the growth and apoptosis of HCC. RNAi of CXCL1 inhibits the growth and apoptosis of tumor cells, which indicates that CXCL1 may be a potential molecular target for use in HCC therapy.
\end{abstract}

\section{Introduction}

Hepatocellular carcinoma (HCC) is one of the most common cancers worldwide and a major cause of cancer-related mortality (1). At the time of diagnosis the majority of patients

Correspondence to: Professor Ke-Qi Han, Department of Oncology, Shanghai Yueyang Hosptail of Integrated Traditional Chinese and Western Medicine, Shanghai University of Traditional Chinese Medicine, Ganhe Road 110, Shanghai 200437, P.R. China E-mail: keqihan@sina.com

*Contributed equally

Key words: chemokine, chemokine receptor, CXCL1, hepatocellular carcinoma is in late stage, the overall survival for HCC patients have also been challenged (2). Studies have showed that chemokine and chemokine receptors play important roles in proliferation and apoptosis of the HCC cells (3-6). Identification of these chemokine receptors may provide potential targets for use in HCC therapy. However, whether CXCL1 participates in proliferation and apoptosis of HCC is yet unclear. Here, we report our findings on gene expression of the pro-angiogenic subgroup of chemokines, the CXCL chemokines. Apart from their proangiogenic function, these chemokines appear to also contribute to tumor cell growth and apoptosis. In our nude mouse model of HCC, we found CXCL1,2,3 and IL-1 $\beta$ to be upregulated in the tumor tissue as compared to the peritumor tissues (7).

Chemokine (C-X-C motif) ligand 1 (CXCL1), binding to the $\mathrm{G}$ protein-coupled chemokine receptor $\mathrm{CXCR} 2$, is involved in fibrogenesis and angiogenesis, except for the role in inflammation and recruitment of neutrophils (8-10). CXCL1 is upregulated in some types of human cancer, including colorectal, bladder, prostate and skin cancers (11-14). A previous study revealed that CXCR2 was overexpressed in HCC, especially in advanced stage (15).

Most inflammatory signals promote tumorigenesis through $\mathrm{NF}-\kappa \mathrm{B}$ and STAT3 activation, both in cancer and stroma cells (16). NF- $\mathrm{NB}$ and STAT3 orchestrates the trafficking of immune and inflammatory cells to sites of inflammatory by upregulating chemokines, which in turn further activate STAT3 signaling (16-18). Chemokines act in an autocrine and a paracrine manner to promote cancer proliferation, invasion, and migration $(8,16,18)$. Upregulated chemokines are expressed in a wide range of human cancer, and associated with a poor prognosis and resistance to therapy $(8-11,18)$.

Until now, there is no study yet regarding the function of CXCL1 in HCC. In the present study, the corresponding molecular mechanism after CXCL1 knockdown using a recombinant lentiviral vector expressing small interference RNA (siRNA) for CXCL1 was also examined. RNA interference (RNAi)-mediated knockdown of CXCL1 in CBRH-7919 cells significantly inhibited the proliferation and induced apoptosis of the cell line in vitro and in vivo. These results provide new evidence of CXCL1 as a promising tumor gene therapeutic target. 


\section{Materials and methods}

HCC cell line. The human HCC cell line CBRH-7919 (Chinese Academy of Sciences Cell Bank, Shanghai, China) was used in this study. Cells were cultured at $37^{\circ} \mathrm{C}$ in a humidified atmosphere with 5\% $\mathrm{CO}_{2}$ in Dulbecco's modified Eagle's medium (DMEM; Gibco BRL, Rockville, MD, USA) supplemented with $10 \%$ fetal bovine serum (FBS) (Life Technologies, Carlsbad, CA, USA), $100 \mathrm{mg} / \mathrm{ml}$ penicillin G, and $50 \mu \mathrm{g} / \mathrm{ml}$ streptomycin (Life Technologies).

Quantitative real-time PCR ( $q R T$-PCR). Total RNA was isolated by TRIzol (Invitrogen, Carlsbad, CA, USA) according to the manufacturer's instructions. Total RNA quality was assessed using Agilent 2100 Bioanalyzer (Agilent Technologies, Inc., Santa Clara, CA, USA), and its concentration was measured by using Nanodrop 2000 spectrophotometer (Thermo Fisher Scientific, Wilmington, DE, USA). RNA was converted to cDNA using the RevertAid First Strand cDNA Synthesis kit (Thermo Fisher Scientific, Waltham, MA, USA). The level of CXCL1 mRNA expression was evaluated by qRT-PCR. The following primers were used for qRT-PCR: CXCL1, 5'-TAGAAGGTGTTGAGCGGGAAG-3' (sense) and 5'-TGAGACGAGAAGGAGCATTGG-3' (antisense); GAPDH, 5'-GTCGGTGTGAACGGATTTG-3' (sense) and 5'-TCCCATTCTCAGCCTTGAC-3' (antisense). qRT-PCR was performed using DyNAmo ColorFlash SYBR-Green qPCR kit on an ABI 7300 system (Applied Biosystems Life Technologies, Foster City, CA, USA).

RNAi. The siRNAs against CXCL1 were designed and ordered from Shanghai GenePharma Co., Ltd. (Shanghai, China). CBRH-7919 cells were transfected with the siRNAs using Lipofectamine RNAiMax (Invitrogen) according to the manufacturer's instructions. Cells were incubated for $48 \mathrm{~h}$, and knockdown efficiency was determined by both qRT-PCR and western blot analysis. The siRNA with the sequence 5'-GTCTCAGGACAGAGAAGTT-3' showed the highest efficiency in the knockdown of CXCL1 and was used in this study.

Cell proliferation assay. Cell proliferation assays were conducted using Cell Counting Kit-8 (CCK-8; Dojindo Laboratories, Kumamoto, Japan). When cells were plated in 96-well plates at $1 \times 10^{4}$ cells/well and incubated for 5 days. Ten microliters of CCK-8 solution was added to each well daily and were incubated for another $2 \mathrm{~h}$. The value of optical density was measured at a wavelength of $450 \mathrm{~nm}$ using a microplate reader (Varioskan Flash 3001; Thermo Fisher Scientific, Marietta, $\mathrm{OH}, \mathrm{USA})$. The amount of the formazan dye generated by the activities of dehydrogenases in cells is directly proportional to the number of living cells. Also, the plate colony formation assay was performed to evaluate the colony formation ability of cells. The tumor cells were cultured at 1,000 cells $/ 5 \mathrm{ml}$ with DMEM and $10 \%$ FBS in a 6-well plate. After 10 days in culture, the cells were fixed with methanol for $10 \mathrm{~min}$ and stained with $1 \%$ crystal violet solution for $20 \mathrm{~min}$ to visualize colonies for counting.

FACS analysis for G0-G1 phase arrest and apoptosis. For cell cycle analysis, CBRH-7919-controls and CBRH-
$\mathbf{A}$

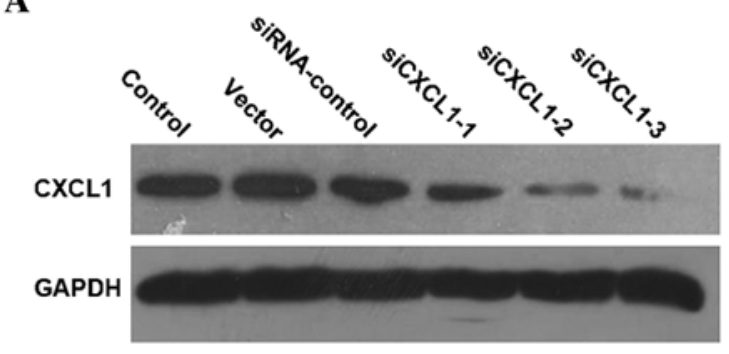

B

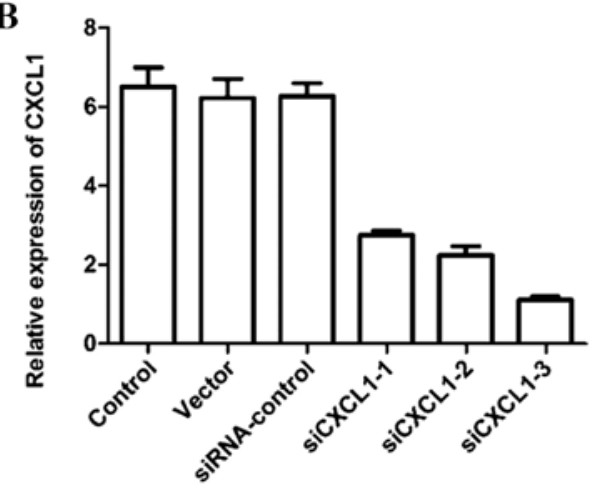

Figure 1. Knockdown of CXCL1 expression by RNAi in CBRH-7919 cells (A) Western blot analysis for CXCL1 expression in cells $48 \mathrm{~h}$ after treating with siCXCL1. (B) mRNA level of CXCL1 at $48 \mathrm{~h}$ post-transfection was analyzed by qRT-PCR.

7919-shRNA were labelled with propidium iodide using a Cycle TEST ${ }^{\mathrm{TM}}$ PLUS DNA reagent kit (BD Pharmingen, San Diego, CA, USA), and then analyzed by FACScan flow cytometer (BD Biosciences, San Jose, CA, USA) according to the manufacturer's guidelines. For apoptosis analysis, cells were stained with Annexin V-FITC and propidium iodide and quantified by FACScan flow cytometer (both from BD Biosciences). All experiments were performed in triplicate.

TUNEL assay. Apoptosis assay was performed using Apo-Direct TUNEL Assay kit (Millipore Corp., Billerica, MA, USA). Cells were harvested and fixed in 4\% PFA for $60 \mathrm{~min}$ at $4{ }^{\circ} \mathrm{C}$, followed by a second fixation in $70 \%(\mathrm{v} / \mathrm{v})$ ethanol overnight at $-20^{\circ} \mathrm{C}$. Cells were then treated by various reagents for a designed period according to the manufacturer's instructions. Finally, cells were analysed by flow cytometry using FACS Vantage machine (BectonDickinson, Franklin Lakes, NJ, USA). CellQuest software (Verity Software House, Inc, Topsham, ME, USA) was used to analyse the data.

Western blotting. Total cell extracts were obtained by treating cells with RIPA buffer (50 nM Tris pH 8.0, $150 \mathrm{mM} \mathrm{NaCl}, 1 \%$ Triton X-100, $0.5 \%$ sodium deoxycholate, $0.1 \%$ SDS, $2 \mathrm{mM}$ EDTA and 5\% glycerol) supplemented with protease and phosphatase inhibitors (Sigma-Aldrich, St. Louis, MO, USA). Equal amounts of protein were separated by SDS-PAGE and then were electro-transferred to polyvinylidene difluoride (PVDF) membranes (Millipore Corp.). The membranes were incubated with various primary antibodies and HRP-conjugated secondary antibodies, and visualized by ECL western blot analysis detection system (Amersham Biosciences, Sweden). 
A
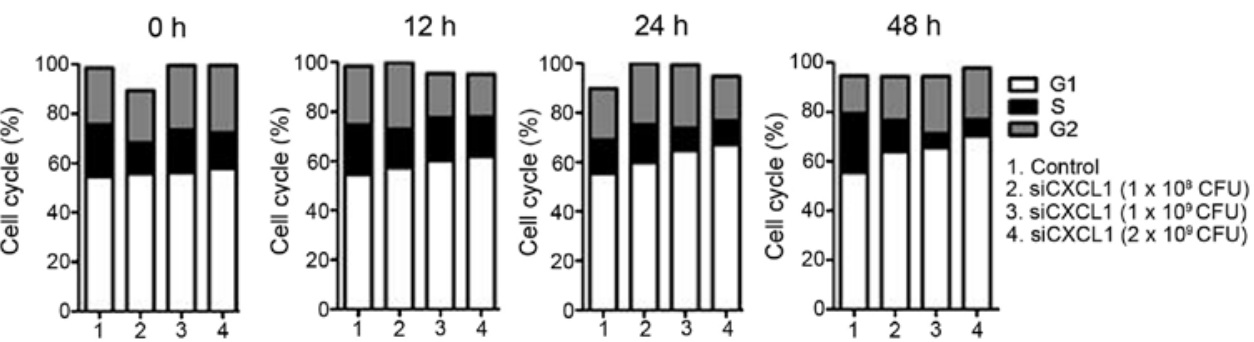

B
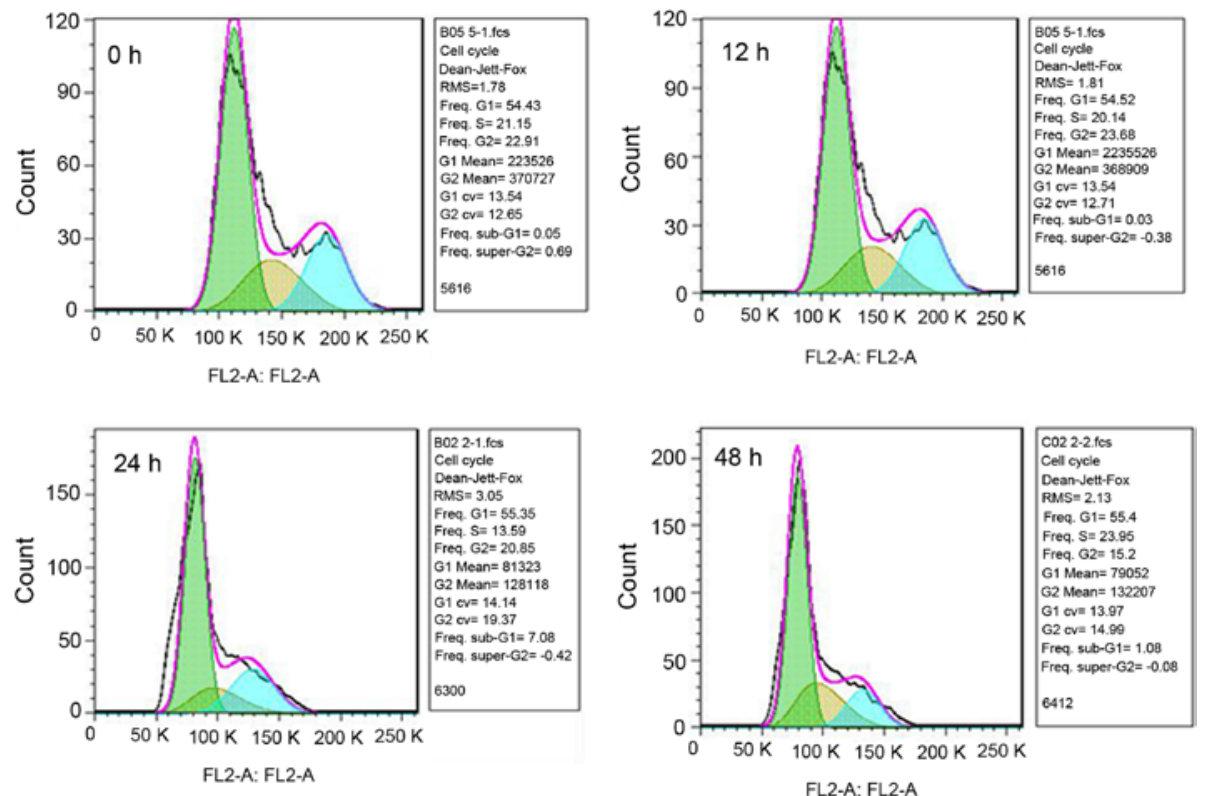

$\mathbf{C}$
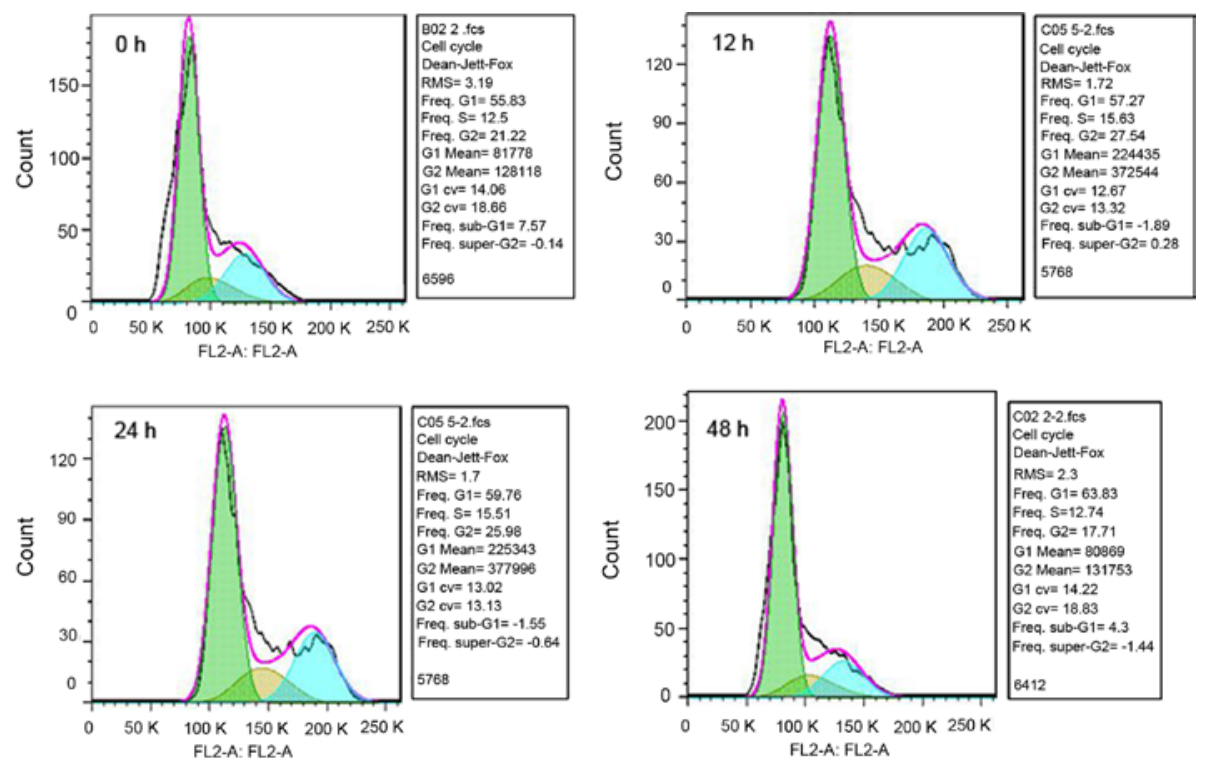

Figure 2. Effect of CXCL1 knockdown on the cell cycle arrest of CBRH-7919 cells. CXCL1 knockdown increased the number of G0/G1 cells and reduced the number of S-phase cells $(\mathrm{P}<0.05)(\mathrm{A})$. Inhibition of CXCL1 expression induced significant cell apoptosis. Mean of triplicates, reproduced in two in dependent experiments: (B) control and (C) siCXCL1 $\left(1 \times 10^{8} \mathrm{CFU}\right)$.

Xenografts in nude mice. Male Balb/c nude mice (4 weeks old, 15-18 g weight) were ordered from Laboratory Animal Service Center of the Medical College of Shanghai. The mice were randomly assigned to the experimental or control group $(\mathrm{n}=4)$. CBRH-7919 cells $\left(2 \times 10^{7}\right.$ cells/mouse) were infected into the left flanks of mice. The tumor sizes were measured using caliper two times every week. The tumor volume was calculated according to following formula: $0.5 \mathrm{x}$ length $\mathrm{x}$ width ${ }^{2}$.

Statistical analyses. All statistical analyses were performed by the Statistical Package of Social Sciences for Windows version 19.0 software (IBM SPSS, Armonk, NY, USA). 
D
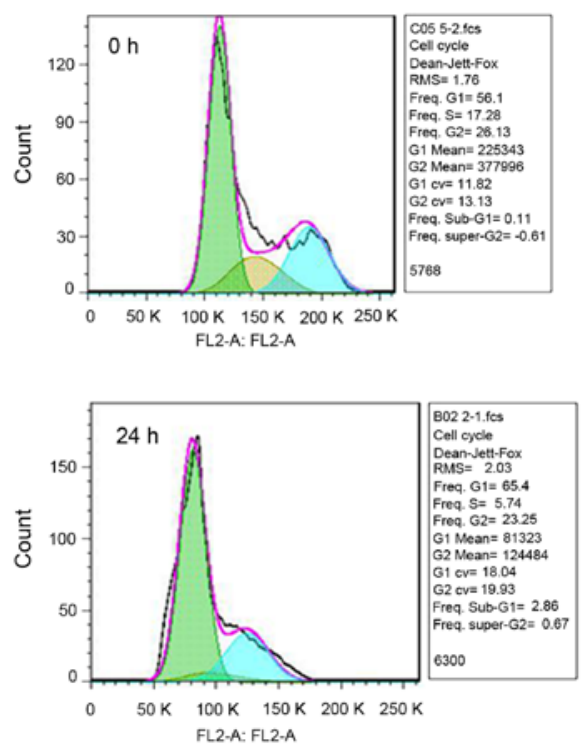

E
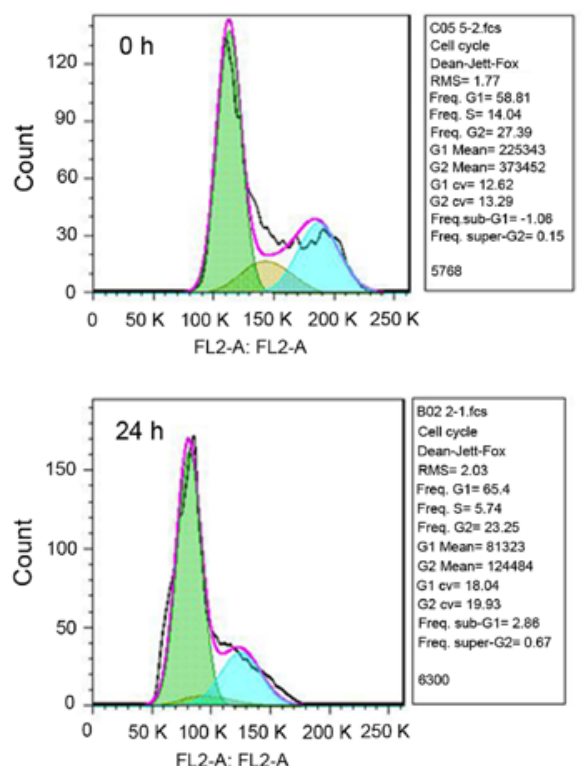
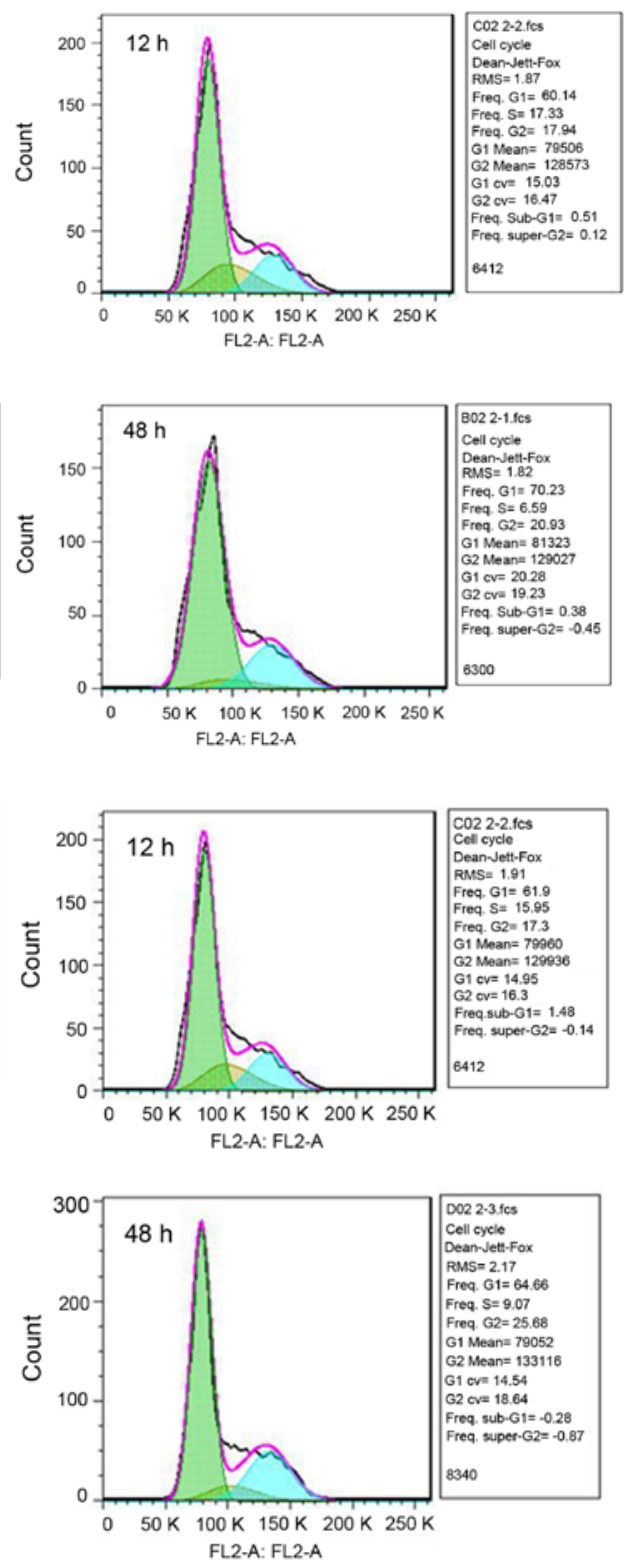

Figure 2. Continued. Effect of CXCL1 knockdown on the cell cycle arrest of CBRH-7919 cells. Inhibition of CXCL1 expression induced significant cell apoptosis. Mean of triplicates, reproduced in two independent experiments: (D) siCXCL1 (1x10 $\mathrm{CFU}$ ) and (E) siCXCL1 (2x10 $\left.0^{8} \mathrm{CFU}\right)$.

A P-value $<0.05$ was considered statistically significant. The data were presented as the mean $\pm \mathrm{SD}$. All data were statistically analyzed by Student's t-test.

\section{Results}

Effect of CXCL1 knockdown on cell cycle regulation and apoptosis in CBRH-7919 cells. To investigate the effects of CXCL1 knockdown on CBRH-7919 cell proliferation and apoptosis, the cell cycle distribution of cells treated with siCXCL1 were examined. The protein and mRNA levels of CXCL1 in cells transfected with siCXCL1 were significantly decreased compared with those in cells treated with corresponding siRNA control (Fig. 1A and B). CXCL1 knockdown increased the number of G0/G1 cells and reduced the number of $\mathrm{S}$-phase cells $(\mathrm{P}<0.05)$ (Fig. 2). Furthermore, inhibition of CXCL1 expression induced significant cell apoptosis (Figs. 3-5), indicating that the growth-inhibitory effect of silencing CXCL1 may be due to G0/G1 cell cycle arrest and increased apoptosis in CBRH-7919 cells. CCK-8 and plate colony formation assays were used to assess the effect of CXCL1 knockdown on the proliferation of CBRH7919 cell lines in vitro. CXCL1 knockdown significantly decreased the proliferation and colony formation of $\mathrm{CBRH}-$ 7919 cells $(\mathrm{P}<0.05)$ (Fig. 6).

Effect of CXCL1 knockdown on tumor growth in a xenograft model. We further investigated the effect of CXCL1 knockdown on tumor cell growth in vivo. Tumors appeared at the site of inoculation within 11-14 days, and mice were observed for 45 days. Both tumor volume and weight in mice administered with CXCL1-siRNA were lower than those in control siRNA treated mice (tumor volume, $603.4 \pm 60.8 \mathrm{~mm}^{3}$ vs. $1,095.1 \pm 102.1 \mathrm{~mm}^{3}$; and tumor weight, $283.5 \pm 21.3 \mathrm{mg}$ vs. $492.5 \pm 43.1 \mathrm{mg}$, respectively). The tumor growth in the CXCL1-siRNA treated mice was significantly decreased 
A

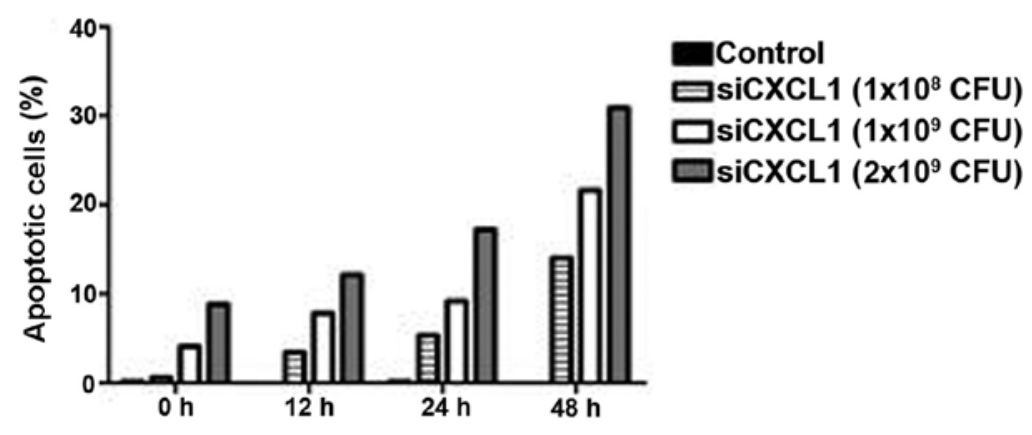

B
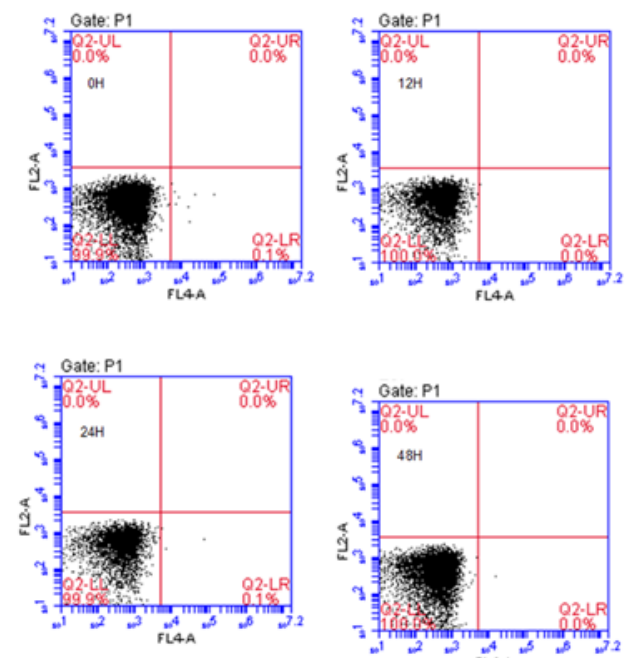

C
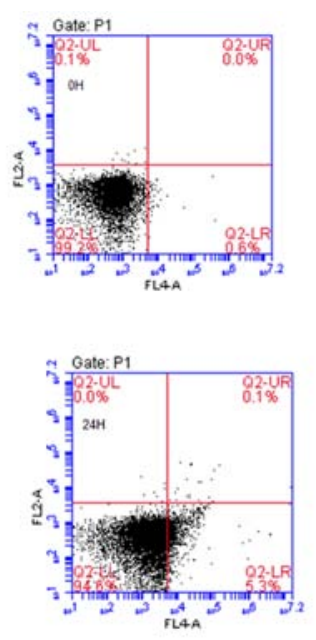
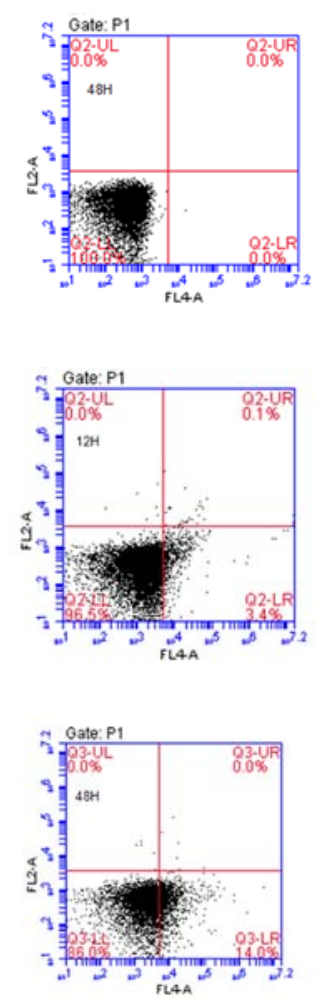

D
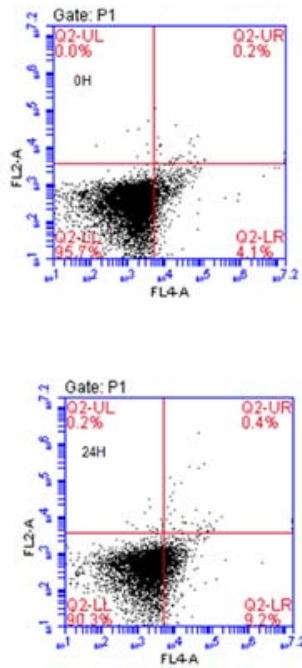

$\mathbf{E}$
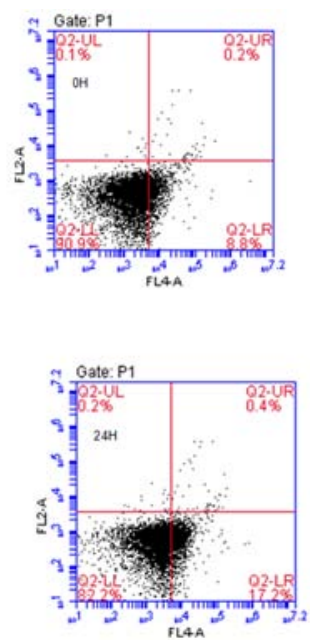
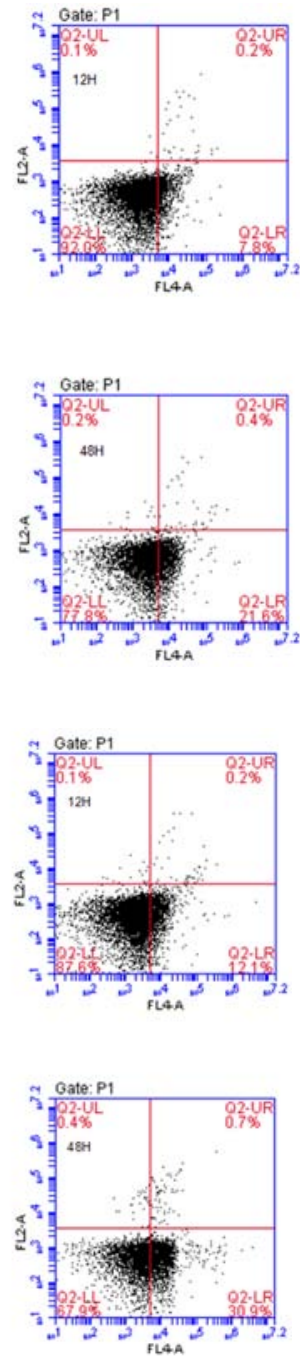

Figure 3 . Effect of CXCL1 knockdown on the cell apoptosis of CBRH-7919 cells. (A) Inhibition of CXCL1 expression induced significant cell apoptosis by

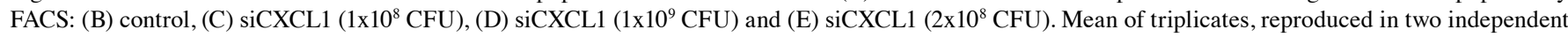
experiments.

compared with mice treated with control siRNA (Fig. 7). These results indicated that CXCL1 might be a molecular target for HCC treatment.

Effects of CXCL1 knockdown on the expression of CXCL2, $C X C L 3$ and $I L-1 \beta$. The levels of CXCL2, CXCL3 and IL-1 $\beta$ were also measured by western blot analysis to enable further consideration of the effect of CXCL1 on the regulation of inflammation in CBRH-7919 cells. Inhibition of CXCL1 expression significantly decreased the protein levels of CXCL2, CXCL3 and IL-1 $\beta$ in siCXCL1-treated cells compared with those in cells treated with control siRNA $(\mathrm{P}<0.05$; Fig. 8A and $\mathrm{B})$.

Effects of CXCL1 knockdown on the activation of autocrine pathway. Since autocrine activation of CXCL1 regulates $\mathrm{NF}-\kappa \mathrm{B}$ expression in colon cancer cells (9), we further investigated whether inhibition of CXCL1 expression affected autocrine activation of the CXCL1 signaling pathway. As shown in Fig. 4, the expression levels of HIF-1 $\alpha$, STAT3 and NF- $\kappa$ B were decreased when CXCL1 was knocked down by RNAi 

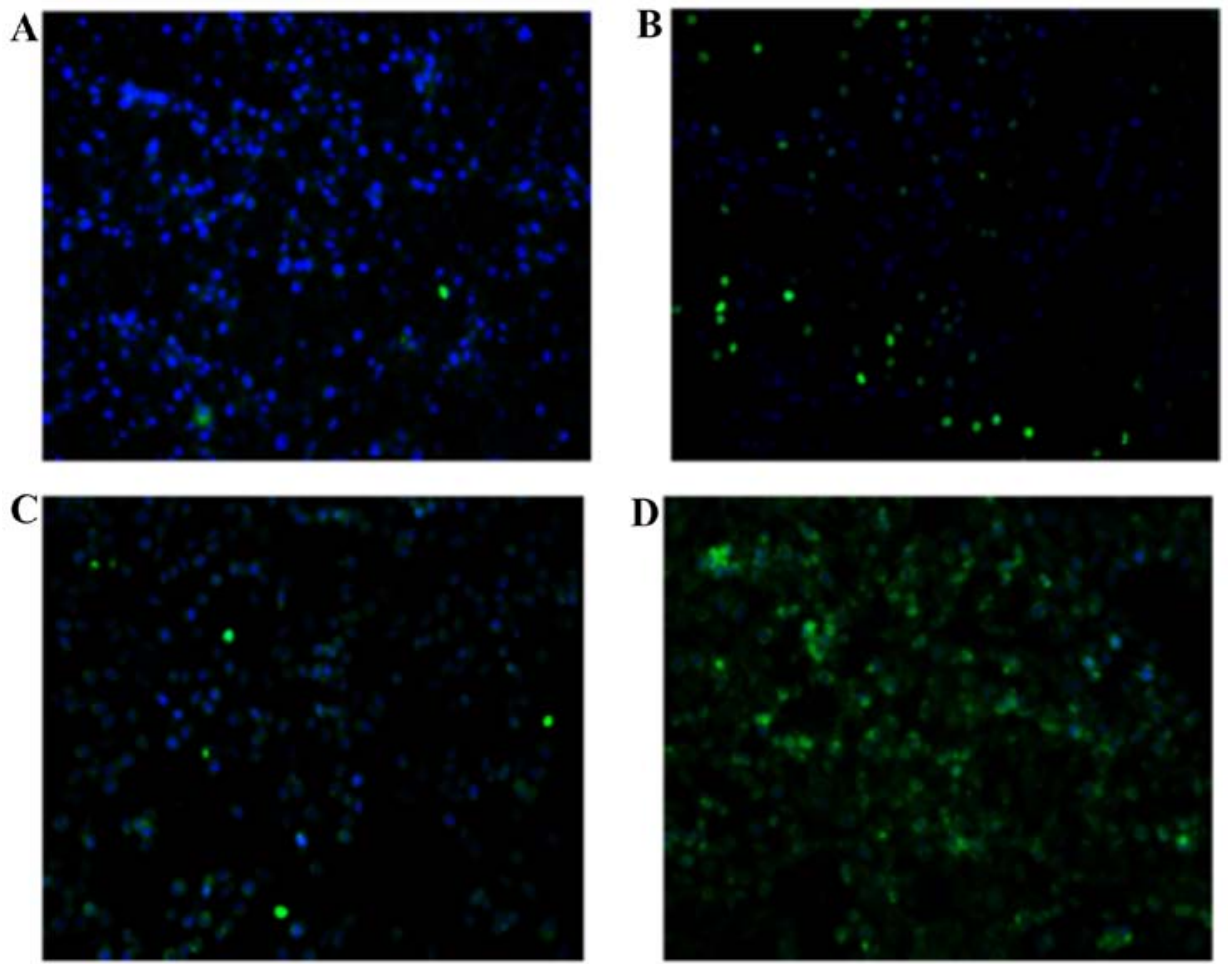

Figure 4. Effect of CXCL1 knockdown on the cell apoptosis of CBRH-7919 cells. Inhibition of CXCL1 expression induced significant cell apoptosis by

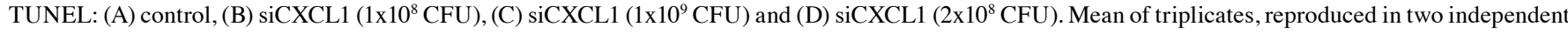
experiments.
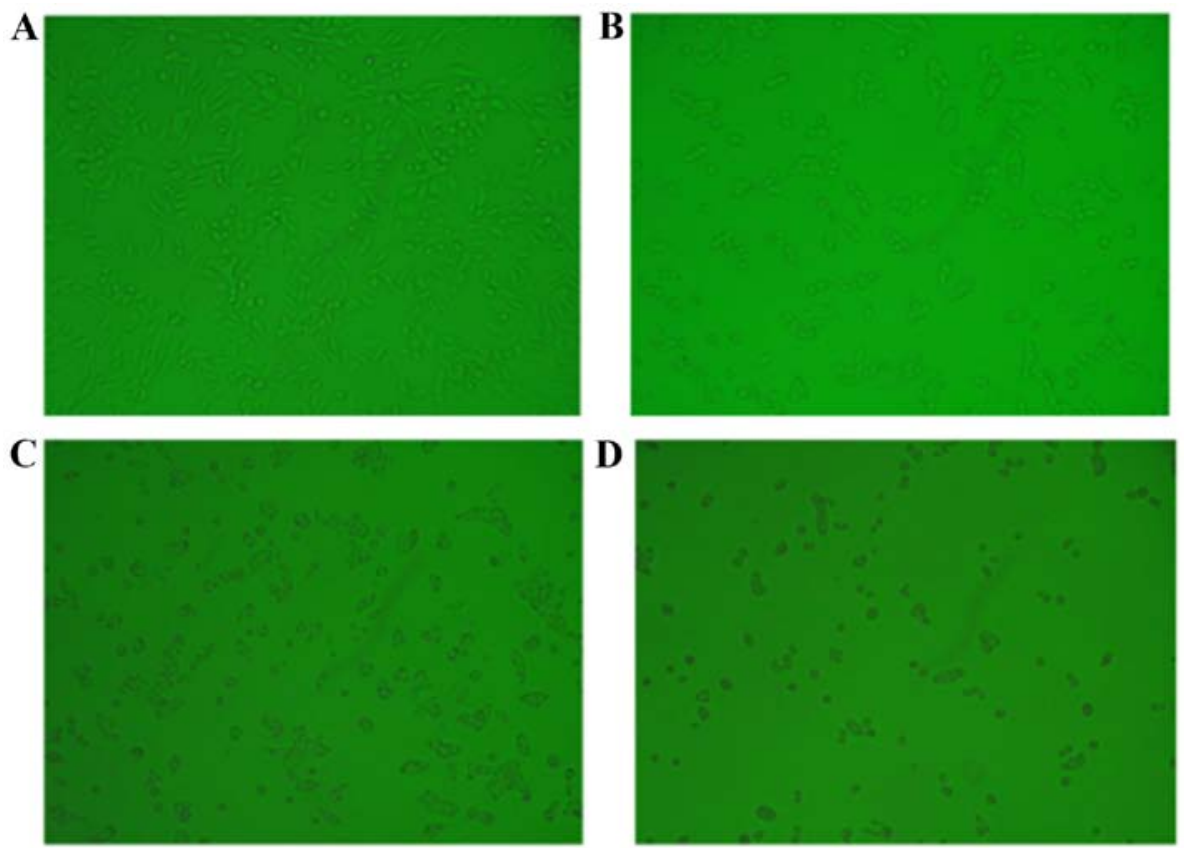

Figure 5. Effect of CXCL1 knockdown on the cell apoptosis of CBRH-7919 cells. Inhibition of CXCL1 expression induced significant cell apoptosis by optical

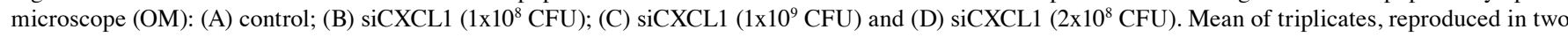
independent experiments.

( $\mathrm{P}<0.05$; Fig. 9). The protein expressions of HIF-1 $\alpha$, STAT3 and NF- $\mathrm{KB}$ decreased to the lowest levels at 12,24 and $48 \mathrm{~h}$, respectively. Therefore, autocrine CXCL1 signaling pathway plays an important role in regulation of $\mathrm{HCC}$ proliferation.

\section{Discussion}

Although efforts have been made to investigate the cellular and molecular pathways involved in cancer-related inflammation 


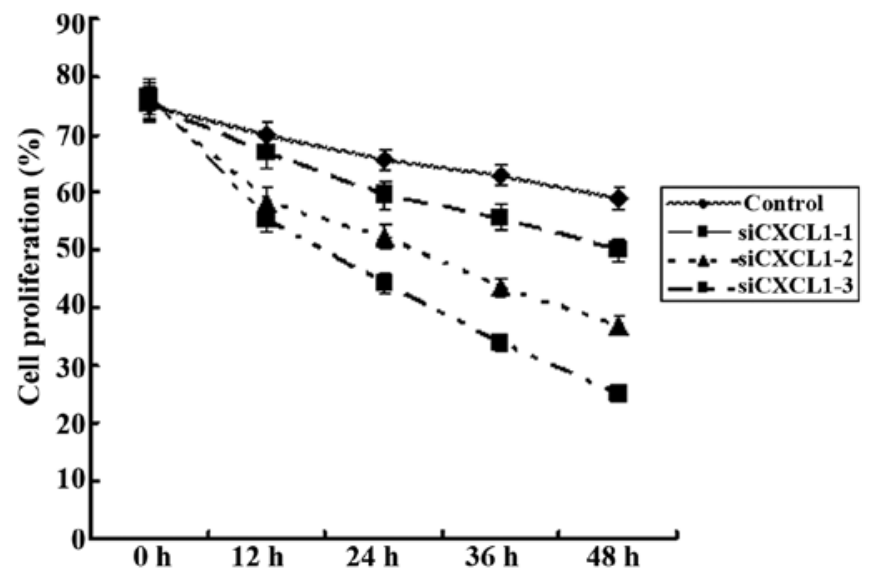

Figure 6. Effect of CXCL1 knockdown on the cell proliferation of CBRH-7919 cells. Inhibition of CXCL1 expression induced significant cell proliferation by

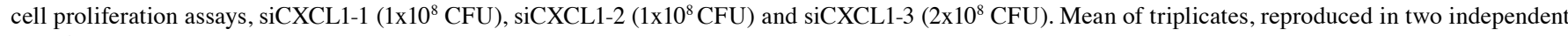
experiments.

A

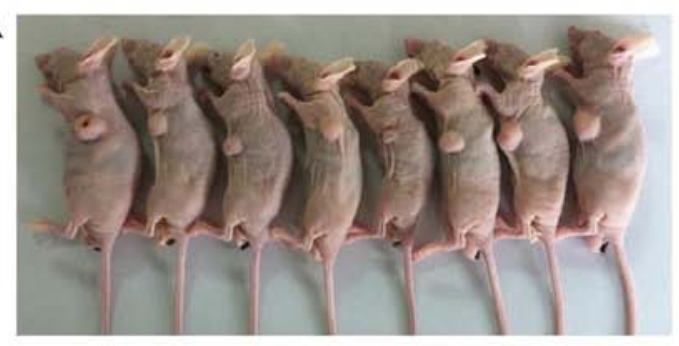

C

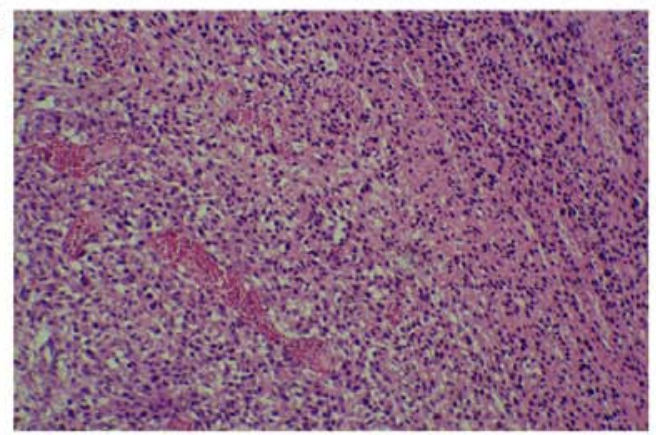

B
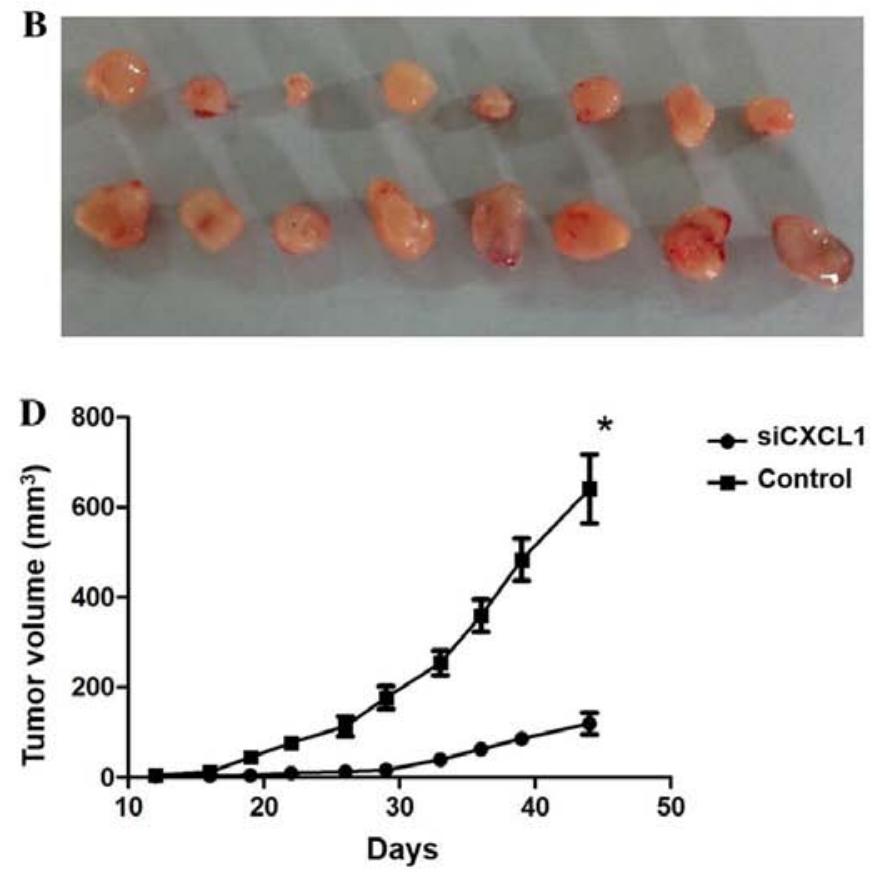

Figure 7. CXCL1 knockdown inhibits xenograft growth of CBRH-7919 cells. (A) Photograph of the mice was taken 30 days after inoculation. (B) Xenografts at sacrifice. (C) H\&E staining of tissue section of the tumor after subcutaneous and intraperitoneal injection of siCXCL cells. (D) Growth curve of the xenografts.

A

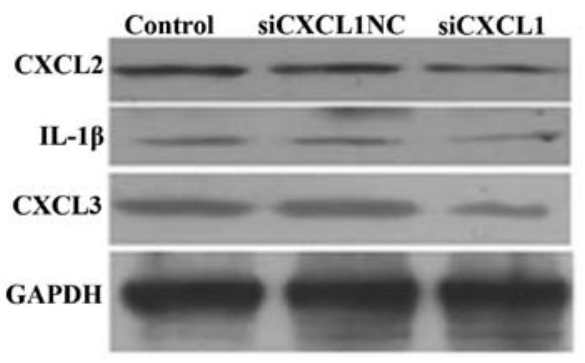

B

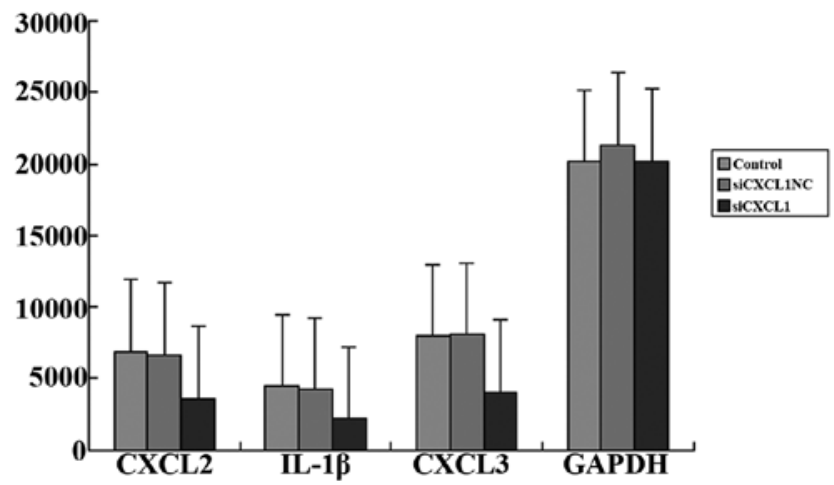

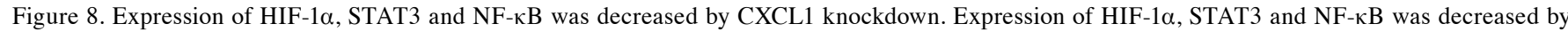
CXCL1 knockdown time- and concentration-dependently. (A) $48 \mathrm{~h}$, siCXCL1 (2x10 $\left.{ }^{8} \mathrm{CFU}\right)$ and (B) 0,24 and $48 \mathrm{~h}$, siCXCL1 (2x10 $\left.{ }^{8} \mathrm{CFU}\right)$. 
A

$\mathbf{O h}$

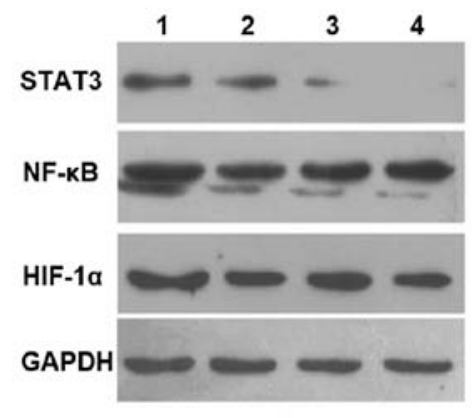

$24 \mathrm{~h}$

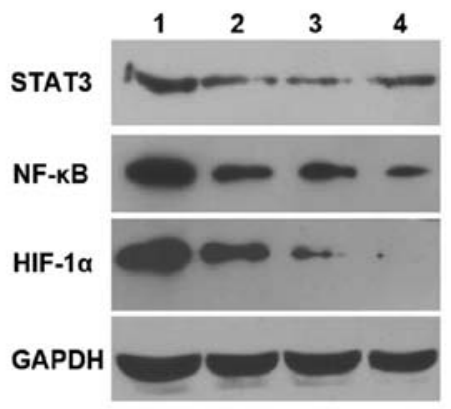

$12 \mathrm{~h}$

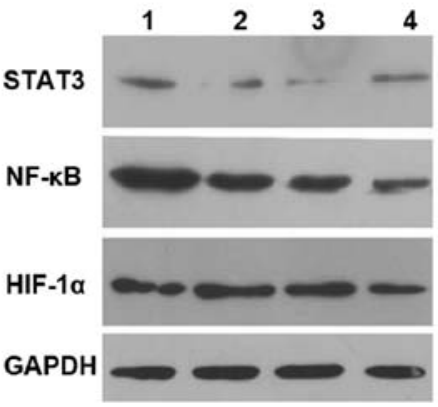

$48 \mathrm{~h}$

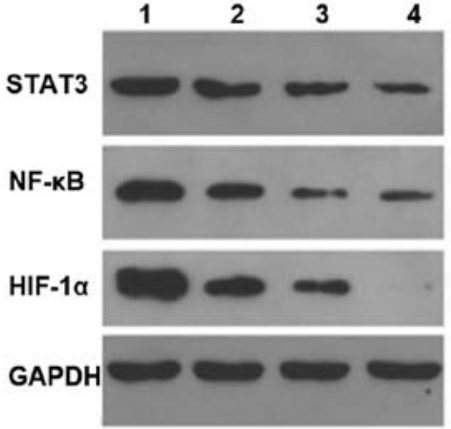

1. Control

2. $\operatorname{siCXCL1}\left(1 \times 10^{8} \mathrm{CFU}\right)$

3. $\operatorname{siCXCL1}\left(1 \times 10^{9} \mathrm{CFU}\right)$

4. $\operatorname{siCXCL1}\left(2 \times 10^{9} \mathrm{CFU}\right)$

B

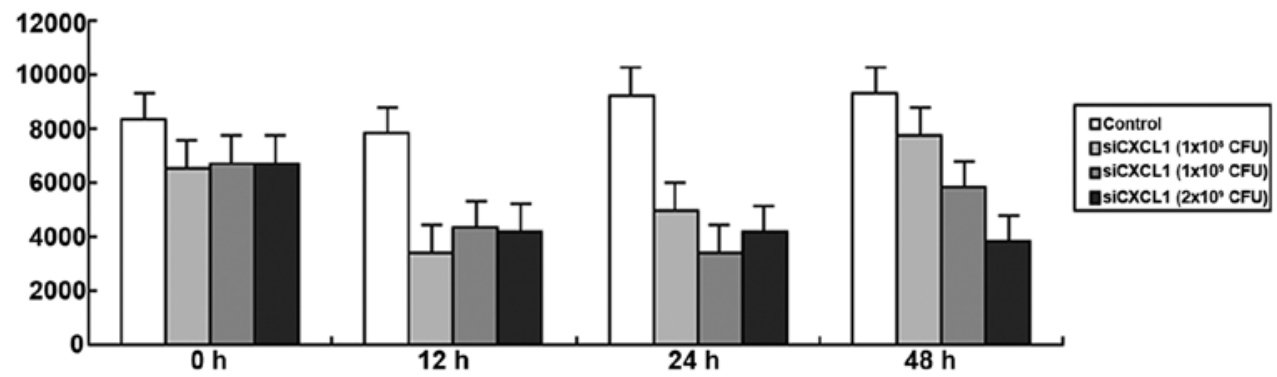

C

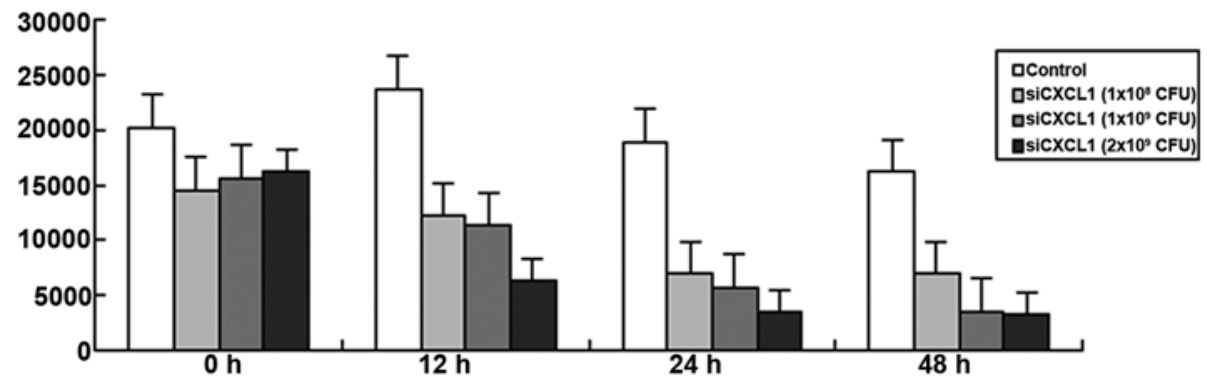

D

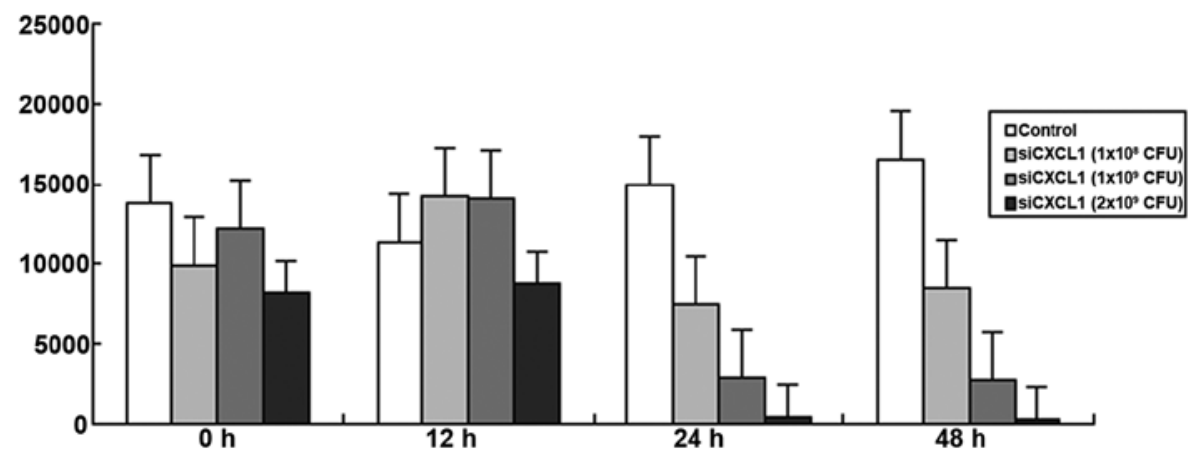

Figure 9. CXCL1 siRNA inhibits expression of CXCL2, CXCL3 and IL-1 $\beta$. (A) CXCL1 siRNA inhibits expression of CXCL2, CXCL3 and IL-1 $\beta$ by 0,12 ,

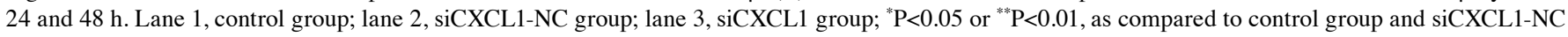
group. (B) NF-kB, (C) HIF-1 $\alpha$ and (D) STAT3; western blot analysis. 
as well as their potential as cancer biomarkers and therapeutic targets, the role of inflammation in cancer is just the tip of the iceberg of mostly unknown mechanisms that contribute to cancer initiation, progression, metastasis, and angiogenesis. In the present study, we found that CXCL1 promotes CBRH-7919 cell proliferation through the downregulation of autocrine CXCL1 signaling pathway. This study may provide new evidence for CXCL1 as a promising therapeutic target for HCC.

Chemokines are produced mainly by cancer and stromal cells (19). They are thought to facilitate the generation and maintenance of anticancer immune responses through the recruitment of immune cells, but they can also result in chronic inflammation and promote tumor growth and metastasis by inducing tumor cell proliferation, migration and angiogenesis (19). CXCL1 is a pleiotropic cytokine that participates in inflammation and modulates neuronal excitability, but also promote tumor development, progression, and metastasis $(12,19-23)$. Downregulation of CXCL1 inhibits cancer cell proliferation, invasion and metastasis, and induces apoptosis $(20,23,24)$. In agreement with previous studies $(20,24)$, downregulation of CXCL1 inhibited the growth of CBRH-7919 cells and induced apoptosis. The results of most recent studies revealed that high expression of CXCL1 was associated with worsened clinical outcome in lung and renal cancers (25). Furthermore, the serum level of CXCL1 was increased in association with cancer progression and metastasis $(26,27)$. On the other hand, Acharyya et al (23) found that overexpression of CXCL1 and 2 contributed to chemoresistance in breast cancer, whereas disrupting the CXCL1 driven paracrine axis improved the efficacy of chemotherapy against breast cancer. The effective of CXCL1 and 2 inhibitors against human cancers underscores the potential application of chemokine-targeted therapy for cancer treatment $(23,24,28)$. CXCL1 might serve as a promising biomarker and therapeutic target for HCC.

Pro-inflammatory cytokines and chemokines activate transcription factors, such as $\mathrm{NF}-\kappa \mathrm{B}$, and STAT3, leading to cancer formation, progression and metastasis (16). In this study, we found reduced expression of HIF-1 $\alpha$, STAT3 and $\mathrm{NF}-\kappa \mathrm{B}$ when CXCL1 was knocked down, indicating that CXCL1 induces the expression of HIF-1 $\alpha$, STAT3 and NF- $\kappa$ B. Furthermore, we observed reduced expression of CXCL2, IL-1 $\beta$ and CXCL3 in CXCL1 knockdown CBRH-7919 cells. Therefore, CXCL1 may regulate the expression of CXCL2, IL-1 $\beta$ and CXCL3 via HIF-1 $\alpha$, STAT3 or NF- $\kappa$ B. Persistent STATS activation is expressed in various types of human cancer, and associated with a poor prognosis and resistance to therapies $(17,29)$. Furthermore, increased NF- $\kappa B$ activity and elevated HIF-1 $\alpha$ expression contribute to the resistance to anticancer drug, and are associated with worse survival in a wide range of cancer types, including HCC (30-32). Recent studies demonstrated that CXCL1 expression was regulated by HIF-1 $\alpha(33,34)$. Activation of HIF-1 $\alpha$, STAT3 and NF- $\kappa$ B pathways via upregulated CXCL1 autocrine signaling protects CBRH-7919 cell from apoptosis. Further studies are warranted to clarify the exact role of CXCL1 in HCC.

In conclusion, our findings are the first evidence that autocrine CXCL1 signaling pathway provides proliferative and survival advantage to HCC. This raises the intriguing possibility that inhibitors targeting CXCL1 and its regulated signaling network might have significant therapeutic activity in HCC.

\section{Acknowledgements}

The present study was supported by the National Natural Scientific Foundation of China (grant no. 81072954).

\section{References}

1. Siegel R, Naishadham D and Jemal A: Cancer statistics, 2013. CA Cancer J Clin 63: 11-30, 2013.

2. Ferlay J, Shin HR, Bray F, Forman D, Mathers C and Parkin DM: Estimates of worldwide burden of cancer in 2008: GLOBOCAN 2008. Int J Cancer 127: 2893-2917, 2010.

3. Li G, Chang H, Zhai YP and Xu W: Targeted silencing of inhibitor of apoptosis proteins by siRNA: A potential anti-cancer strategy for hepatocellular carcinoma. Asian Pac J Cancer Prev 14: 4943-4952, 2013.

4. Shi YH, Ding WX, Zhou J, He JY, Xu Y, Gambotto AA, Rabinowich H, Fan J and Yin XM: Expression of X-linked inhibitor-of-apoptosis protein in hepatocellular carcinoma promotes metastasis and tumor recurrence. Hepatology 48: 497-507, 2008.

5. Zhang L, Zhao Z, Feng Z, Yin N, Liu G and Shan B: RNA interference-mediated silencing of Stat5 induces apoptosis and growth suppression of hepatocellular carcinoma cells. Neoplasma 59: 302-309, 2012.

6. Strieter RM, Burdick MD, Mestas J, Gomperts B, Keane MP and Belperio JA: Cancer CXC chemokine networks and tumour angiogenesis. Eur J Cancer 42: 768-78, 2006.

7. Han KQ, He XQ, Ma MY, Guo XD, Zhang XM, Chen J, Han H, Zhang WW, Zhu QG, Nian H, et al: Inflammatory microenvironment and expression of chemokines in hepatocellular carcinoma. World J Gastroenterol 21: 4864-4874, 2015.

8. Ghanem I, Riveiro ME, Paradis V, Faivre S, de Parga PM and Raymond E: Insights on the CXCL12-CXCR4 axis in hepatocellular carcinoma carcinogenesis. Am J Transl Res 6: 340-352, 2014.

9. An H, Xu L, Zhu Y, Lv T, Liu W, Liu Y, Liu H, Chen L, Xu J and Lin Z: High CXC chemokine receptor 4 expression is an adverse prognostic factor in patients with clear-cell renal cell carcinoma. Br J Cancer 110: 2261-2268, 2014.

10. Rentoft M, Coates PJ, Loljung L, Wilms T, Laurell G and Nylander K: Expression of CXCL10 is associated with response to radiotherapy and overall survival in squamous cell carcinoma of the tongue. Tumour Biol 35: 4191-4198, 2014.

11. Verbeke H, Struyf S, Laureys $G$ and Van Damme J: The expression and role of CXC chemokines in colorectal cancer. Cytokine Growth Factor Rev 22: 345-358, 2011.

12. Miyake M, Lawton A, Goodison S, Urquidi V and Rosser CJ: Chemokine (C-X-C motif) ligand 1 (CXCL1) protein expression is increased in high-grade prostate cancer. Pathol Res Pract 210: 74-75, 2014.

13. Dhawan P and Richmond A: Role of CXCL1 in tumorigenesis of melanoma. J Leukoc Biol 72: 9-18, 2002.

14. Miyake M, Lawton A, Goodison S, Urquidi V, Gomes-Giacoia E, Zhang G, Ross S, Kim J and Rosser CJ: Chemokine (C-X-C) ligand 1 (CXCL1) protein expression is increased in aggressive bladder cancers. BMC Cancer 13: 322, 2013.

15. Liu Z, Yang L, Xu J, Zhang X and Wang B: Enhanced expression and clinical significance of chemokine receptor CXCR2 in hepatocellular carcinoma. J Surg Res 166: 241-246, 2011.

16. Grivennikov SI, Greten FR and Karin M: Immunity, inflammation, and cancer. Cell 140: 883-899, 2010.

17. Yu H, Pardoll D and Jove R: STATs in cancer inflammation and immunity: A leading role for STAT3. Nat Rev Cancer 9: 798-809, 2009.

18. Wani N, Nasser MW, Ahirwar DK, Zhao H, Miao Z, Shilo K and Ganju RK: C-X-C motif chemokine $12 / \mathrm{C}-\mathrm{X}-\mathrm{C}$ chemokine receptor type 7 signaling regulates breast cancer growth and metastasis by modulating the tumor microenvironment. Breast Cancer Res 16: R54, 2014.

19. Boissière-Michot F, Lazennec G, Frugier H, Jarlier M, Roca L, Duffour J, Du Paty E, Laune D, Blanchard F, Le Pessot F, et al: Characterization of an adaptive immune response in microsatellite-instable colorectal cancer. OncoImmunology 3: e29256, 2014. 
20. Bandapalli OR, Ehrmann F, Ehemann V, Gaida M, MacherGoeppinger S, Wente M, Schirmacher $\mathrm{P}$ and Brand $\mathrm{K}$ : Down-regulation of CXCL1 inhibits tumor growth in colorectal liver metastasis. Cytokine 57: 46-53, 2012.

21. Wang JG, Strong JA, Xie W, Yang RH, Coyle DE, Wick DM, Dorsey ED and Zhang JM: The chemokine CXCL1/growth related oncogene increases sodium currents and neuronal excitability in small diameter sensory neurons. Mol Pain 4: 38, 2008

22. Benelli R, Stigliani S, Minghelli S, Carlone S and Ferrari N: Impact of CXCL1 overexpression on growth and invasion of prostate cancer cell. Prostate 73: 941-951, 2013.

23. Acharyya S, Oskarsson T, Vanharanta S, Malladi S, Kim J, Morris PG, Manova-Todorova K, Leversha M, Hogg N, Seshan VE, et al: A CXCL1 paracrine network links cancer chemoresistance and metastasis. Cell 150: 165-178, 2012.

24. Killian PH, Kronski E, Michalik KM, Barbieri O, Astigiano S, Sommerhoff CP, Pfeffer U, Nerlich AG and Bachmeier BE: Curcumin inhibits prostate cancer metastasis in vivo by targeting the inflammatory cytokines CXCL1 and -2. Carcinogenesis 33: 2507-2519, 2012

25. Pecot CV, Rupaimoole R, Yang D, Akbani R, Ivan C, Lu C, Wu S, Han HD, Shah MY, Rodriguez-Aguayo C, et al: Tumour angiogenesis regulation by the miR-200 family. Nat Commun 4: 2427,2013

26. Jung JJ, Noh S, Jeung HC, Jung M, Kim TS, Noh SH, Roh JK, Chung HC and Rha SY: Chemokine growth-regulated oncogene 1 as a putative biomarker for gastric cancer progression. Cancer Sci 101: 2200-2206, 2010.

27. Divella R, Daniele A, Savino E, Palma F, Bellizzi A, Giotta F, Simone G, Lioce M, Quaranta M, Paradiso A, et al: Circulating levels of transforming growth factor-beta (TGF- $\beta$ ) and chemokine (C-X-C motif) ligand-1 (CXCL1) as predictors of distant seeding of circulating tumor cells in patients with metastatic breast cancer. Anticancer Res 33: 1491-1497, 2013.
28. Kavandi L, Collier MA, Nguyen $\mathrm{H}$ and Syed V: Progesterone and calcitriol attenuate inflammatory cytokines CXCL1 and CXCL2 in ovarian and endometrial cancer cells. J Cell Biochem 113: 3143-3152, 2012

29. Yu H and Jove R: The STATs of cancer - new molecular targets come of age. Nat Rev Cancer 4: 97-105, 2004.

30. Liang Y, Zheng T, Song R, Wang J, Yin D, Wang L, Liu H, Tian L, Fang X, Meng X, et al: Hypoxia-mediated sorafenib resistance can be overcome by EF24 through Von Hippel-Lindau tumor suppressor-dependent HIF-1 $\alpha$ inhibition in hepatocellular carcinoma. Hepatology 57: 1847-1857, 2013.

31. Novell A, Martinez-Alonso M, Mira M, Tarragona J, Salud A and Matias-Guiu X. Prognostic value of c-FLIPL/s, HIF-1 $\alpha$, and NF- $\kappa \beta$ in stage II and III rectal cancer. Virchows Arch 464: 645-654, 2014.

32. Chen SP, Yang Q, Wang CJ, Zhang LJ, Fang Y, Lei FY, Wu S, Song LB, Guo X and Guo L: Transducin $\beta$-like 1 X-linked receptor 1 suppresses cisplatin sensitivity in nasopharyngeal carcinoma via activation of NF- $\kappa$ B pathway. Mol Cancer 13: 195 , 2014.

33. Byrne AJ, Jones CP, Gowers K, Rankin SM and Lloyd CM: Lung macrophages contribute to house dust mite driven airway remodeling via HIF-1 $\alpha$. PLoS One 8: e69246, 2013.

34. Wang J, Yu F, Jia X, Iwanowycz S, Wang Y, Huang S, Ai W and Fan D: MicroRNA-155 deficiency enhances the recruitment and functions of myeloid-derived suppressor cells in tumor microenvironment and promotes solid tumor growth. Int J Cancer 136: E602-E613, 2014. 